\title{
Glutamate Transporters Regulate Extrasynaptic NMDA Receptor Modulation of Kv2.1 Potassium Channels
}

\author{
Patrick J. Mulholland, Ezekiel P. Carpenter-Hyland, Matthew C. Hearing, Howard C. Becker, John J. Woodward, and \\ L. Judson Chandler \\ Department of Neurosciences and Center for Drug and Alcohol Programs, Medical University of South Carolina, Charleston, South Carolina 29425
}

Delayed-rectifier Kv2.1 potassium channels regulate somatodendritic excitability during periods of repetitive, high-frequency activity. Recent evidence suggests that Kv2.1 channel modulation is linked to glutamatergic neurotransmission. Because NMDA-type glutamate receptors are critical regulators of synaptic plasticity, we investigated NMDA receptor modulation of Kv2.1 channels in rodent hippocampus and cortex. Bath application of NMDA potently unclustered and dephosphorylated Kv2.1 and produced a hyperpolarizing shift in voltage-dependent activation of voltage-sensitive potassium currents $\left(I_{\mathrm{K}}\right)$. In contrast, driving synaptic activity in $\mathrm{Mg}^{2+}$-free media to hyperactivate synaptic NMDA receptors had no effect on Kv2.1 channels, and moderate pentylenetetrazole-induced seizure activity in adult mice did not dephosphorylate hippocampal Kv2.1 channels. Selective activation of extrasynaptic NMDA receptors unclustered and dephosphorylated Kv2.1 channels and produced a hyperpolarizing shift in neuronal $I_{\mathrm{K}}$. In addition, inhibition of glutamate uptake rapidly activated NMDA receptors and dephosphorylated Kv2.1 channels. These observations demonstrate that regulation of intrinsic neuronal activity by Kv2.1 is coupled to extrasynaptic but not synaptic NMDA receptors. These data support a novel mechanism for glutamate transporters in regulation of neuronal excitability and plasticity through extrasynaptic NMDA receptor modulation of Kv2.1 channels.

Key words: Kv2.1 channels; NMDA receptors; extrasynaptic; astroglia; glutamate transporters; extracellular

\section{Introduction}

Delayed-rectifier voltage-dependent potassium $(\mathrm{Kv})$ channels dynamically regulate diverse aspects of neuronal excitability. This regulation is dependent on channel subtype, location, and gating properties. Delayed-rectifier Kv2.1 channels are the principal component of voltage-sensitive potassium currents $\left(I_{\mathrm{K}}\right)$ in hippocampus and cortex (Murakoshi and Trimmer, 1999; Du et al., 2000). Kv2.1 channels are found in large clusters (up to $2 \mu \mathrm{m}$ in diameter) on the soma and proximal dendrites of pyramidal neurons in which they are constitutively maintained in a highly phosphorylated state (Misonou et al., 2004, 2005b, 2006). The somatodendritic location of Kv2.1 channels allows for control of somatic subthreshold excitatory responses and, ultimately, regulation of action potential initiation (Murakoshi and Trimmer, 1999).

Studies investigating somatodendritic $I_{\mathrm{K}}$ suggest that Kv2.1 channels are slow to respond and require periods of repetitive, high-frequency synaptic activity for activation (Du et al., 2000; Misonou et al., 2004, 2005b). This has led to the proposal that Kv2.1 channels dynamically control sustained excitability by po-

Received May 20, 2008; revised June 23, 2008; accepted July 23, 2008.

This work was supported by National Institute on Alcohol Abuse and Alcoholism Grants AA010983 (L.J.C.) and AA09986 (J.J.W.). P.J.M. is supported by National Research Service Award AA016450. We thank Nick Luong for his technical assistance in performing some of these experiments.

Correspondence should be addressed to L. Judson Chandler, Department of Neurosciences and Center for Drug and Alcohol Programs, 67 President Street, Medical University of South Carolina, Charleston, SC. E-mail: chandj@musc.edu.

DOI:10.1523/JNEUROSCI.2405-08.2008

Copyright $\odot 2008$ Society for Neuroscience $\quad$ 0270-6474/08/288801-09\$15.00/0 tently reducing the propensity for subsequent action potential generation (Surmeier and Foehring, 2004; Misonou et al., 2005a). Indeed, knockdown of Kv2.1 in organotypic hippocampal slices increased excitability of CA1 pyramidal neurons during highfrequency, but not low-frequency, stimulation (Du et al., 2000). In addition, ischemic conditions produced calcineurindependent dephosphorylation and unclustering of Kv2.1, hyperpolarizing shifts in voltage-dependent activation of $I_{\mathrm{K}}$, and reduced spontaneous calcium transients (Misonou et al., 2005b). Interestingly, the reduction in calcium transients was prevented by tetraethylammonium, which blocks most of $I_{\mathrm{K}}$, but not by the selective BK channel inhibitor iberiotoxin, indirectly implicating Kv2.1 channels in suppression of neuronal excitability after ischemia (Misonou et al., 2005b).

Recent evidence suggests that neuronal activity and in particular glutamatergic neurotransmission regulate clustering, phosphorylation, and the functional properties of Kv2.1 channels (Misonou et al., 2004, 2006). Thus, the present study investigated the coupling of NMDA-type glutamate receptors to modulation of Kv2.1 channels in rodent hippocampus and cortex. Given the suggestion that Kv2.1 channels may link elevations in glutamate to suppressed burst firing as part of a homeostatic feedback system, we also examined alterations in Kv2.1 during periods of synaptic hyperactivity.

\section{Materials and Methods}

Materials. Anti-Kv2.1 rat polyclonal and mouse monoclonal antibodies were generously provided by J. S. Trimmer (University of California, Davis, Davis, CA) or were purchased from NeuroMab (University of 
California, Davis and Antibodies Inc.). A complete list of materials can be found in supplemental Materials and Methods (available at www. jneurosci.org as supplemental material).

Preparation and treatment of cultures. Hippocampal and cortical neuronal cultures and organotypic hippocampal slices were prepared according to previously reported methods with minor modifications (Chandler et al., 1997; Carpenter-Hyland et al., 2004; Mulholland et al., 2005). Complete description of culturing methods can be found in supplemental Materials and Methods (available at www.jneurosci.org as supplemental material). All experiments were completed in at least triplicate, and data were collected from at least three different culture preparations.

To examine changes in phosphorylation, clustering, and functional properties of Kv2.1, cultures were washed twice with $1 \mathrm{ml}$ of $25 \mathrm{~mm}$ HEPES incubation buffer containing $140 \mathrm{~mm} \mathrm{NaCl}, 5.4 \mathrm{~mm} \mathrm{KCl}, 1.8 \mathrm{~mm}$ $\mathrm{CaCl}_{2}, 10 \mu \mathrm{M}$ glycine, $15 \mathrm{~mm}$ glucose, and $2 \mathrm{~mm} \mathrm{MgCl}_{2}, \mathrm{pH}$ 7.4. After a brief acclimation period in HEPES buffer, cultures were then subjected to various treatments in HEPES buffer without $\mathrm{Mg}^{2+}$ as indicated in Results. In experiments examining the selective activation of extrasynaptic NMDA receptors, synaptic NMDA receptors were first blocked in $\mathrm{Mg}^{2+}$ free buffer with $10 \mu \mathrm{M}$ MK-801 [(+)-5-methyl-10,11-dihydro-5Hdibenzo [a,d] cyclohepten-5,10-imine maleate] in the presence of $2 \mu \mathrm{M}$ tetrodotoxin (TTX) (Lu et al., 2001; Tovar and Westbrook, 2002; Carpenter-Hyland et al., 2004). After $10 \mathrm{~min}$, the MK-801-containing buffer was replaced with MK-801- and $\mathrm{Mg}^{2+}$-free buffer, and the unblocked extrasynaptic receptors were activated by bath application of NMDA. In addition to a reduction in whole-cell NMDA currents after synaptic trapping, we demonstrated previously in our cultures that the NMDA component of spontaneous EPSCs (sEPSCs) was markedly reduced and remained absent for $>30$ min after MK-801 washout (Carpenter-Hyland et al., 2004; Mulholland et al., 2008). A complete description of methods for chronic ethanol treatment of cultures can be found in supplemental Materials and Methods (available at www. jneurosci.org as supplemental material).

Kv2.1 cluster analysis. Immunostaining of Kv2.1 clustering was performed using 14- to 17-d-old low-density hippocampal cultures following previously described methods (Carpenter-Hyland et al., 2004; Carpenter-Hyland and Chandler, 2006) Briefly, neurons were rinsed twice in ice-cold PBS (in mM: $136 \mathrm{NaCl}, 2.6 \mathrm{KCl}, 1.8 \mathrm{KH}_{2} \mathrm{HPO}_{4}$, and 10 $\mathrm{Na}_{2} \mathrm{HPO}_{4}, \mathrm{pH} 7.4$ ) and fixed for $15 \mathrm{~min}$ in $4 \%$ paraformaldehyde/4\% sucrose (PFA-S). Neurons were then permeabilized for $5 \mathrm{~min}$ in PBS with $0.2 \%$ Triton X-100. After incubation in 5\% normal donkey serum (NDS) for $1 \mathrm{~h}$, neurons were incubated overnight with rabbit anti-Kv2.1 (1: $1000)$ at $4^{\circ} \mathrm{C}$. After overnight incubation using CoverWell incubation chambers (Invitrogen), the chambers were removed and the dishes were incubated with Alexa 488 goat anti-rabbit (1:4000) secondary antibody at room temperature for $1 \mathrm{~h}$. Dishes were then mounted with $1,4-$ daizabicyclo $(2,2,2)$ octane-containing mounting media and stored at $4^{\circ} \mathrm{C}$ until imaging. Imaging of hippocampal neurons was performed on a Zeiss LSM 510 confocal microscope using a $63 \times$ objective (numerical aperture 1.4) and a threefold zoom setting. Laser and detector settings were retained for all images collected within a set of experimental dishes. Control and treatment groups were always run in parallel within the same immunocytochemical procedure. Colocalization analyses of Kv2.1 with NR1 or PSD-95 in hippocampal neurons was accomplished in the same manner using $-20^{\circ} \mathrm{C}$ methanol fix and mouse anti-NR1 (1:100; BD Biosciences PharMingen) or mouse anti-PSD-95 (1:100; Sigma-Aldrich) primary antibodies with Alexa 594 goat anti-mouse (1:1000) secondary antibody. Image analysis of clustering was restricted to the soma and proximal dendrites. MetaMorph version 4.6 software (Molecular Devices) was used to interactively define Kv2.1 clusters at twofold above cytoplasmic background for evaluation of cluster size and density, following previously described methods (Carpenter-Hyland et al., 2004; Carpenter-Hyland and Chandler, 2006). Data collected in MetaMorph were exported to Prism (GraphPad Software) for statistical analysis. Confocal images were prepared for display in Adobe Photoshop CS (Adobe Systems).

Immunostaining of Kv2.1 clustering in hippocampal slices was performed following the aforementioned procedures with minor modifica- tions. After treatment, slices were washed once in ice-cold PBS and fixed in PFA-S for $1 \mathrm{~h}$ at $4^{\circ} \mathrm{C}$. The slices were then washed once before gently removing the slices from the membranes. Free-floating slices were placed into PBS containing 5\% NDS and $0.3 \%$ Triton X-100 for $2 \mathrm{~h}$ at $4^{\circ} \mathrm{C}$. Free-floating slices were incubated overnight with mouse anti-Kv2.1 (1: 5000; NeuroMab and Antibodies Inc.) at $4^{\circ} \mathrm{C}$. Slices were washed in PBS before incubation in Alexa 488 goat anti-mouse secondary antibody (1: $1000)$ for $2 \mathrm{~h}$ at room temperature. Slices were then washed in PBS and mounted using Prolong Gold antifade reagent (Invitrogen) on subbed slides and stored at $4^{\circ} \mathrm{C}$ until imaging.

Colocalization analysis of Kv2.1 channels with NR1 or PSD-95. We sought to determine whether Kv2.1 channels in hippocampal neurons colocalize with (1) NMDA receptors containing the obligatory NR1 subunit, and (2) the postsynaptic density scaffolding protein PSD-95. The extent of colocalized puncta of Kv2.1 and NR1 or PSD-95 was measured using the colocalization module of Imaris 5.0.2. software, 64-bit version (Bitplane). The colocalization module uses an iterative automatic process to threshold background intensities in each channel that avoids investigator bias (Costes et al., 2004; Marvizón et al., 2007), and the amount of colocalized voxels was determined by two different measurements. First, a Pearson's coefficient in voxels with colocalization was determined that measures the correlation between the intensities of the colocalized voxels between the two channels. Thus, the Pearson's coefficient for two proteins that are highly colocalized would theoretically have a Pearson's coefficient value near +1 . Second, the percentage of material colocalized was determined in the same images. This method accounts for the intensity and number of colocalized voxels. In this case, if two proteins were highly colocalized, the percentage of material colocalized would be near $100 \%$. The automatic thresholding feature was first used to threshold the background in each channel, and a new colocalized channel was generated. The colocalization module then calculates the Pearson's coefficient and percentage of material colocalized from the two channels and the new colocalized channel, and the Pearson's coefficient and percentage of material colocalized values were exported to an Excel (Microsoft) file.

Kv2.1 dephosphorylation. The shift in Kv2.1 electrophoretic mobility (referred to as dephosphorylated Kv2.1) was determined by SDS-PAGE using mouse anti-Kv2.1 primary antibody (for complete details on protein preparation and SDS-PAGE methods, see supplemental Materials and Methods, available at www.jneurosci.org as supplemental material). Data are expressed as a ratio of the integrated density of phosphorylated $\mathrm{Kv} 2.1$ to total Kv2.1. Optical density values were used to determine total expression of all Kv2.1 bands in the membrane fraction. Statistical analyses of integrated and optical density values for Kv2.1 were performed using Prism version 4.03 (GraphPad Software).

Whole-cell patch-clamp electrophysiology. In experiments measuring voltage-dependent activation of $I_{\mathrm{K}}$, neurons were held at $-80 \mathrm{mV}$ before a conditioning prepulse to $-10 \mathrm{mV}$ for $30 \mathrm{~ms}$ to inactivate the fast transient component of total $I_{\mathrm{K}}$. After a delay of $50 \mathrm{~ms}$, the delayed rectifier component of $I_{\mathrm{K}}$ was then evoked by application of depolarizing voltage commands to potentials between -80 to $+80 \mathrm{mV}$ in $20 \mathrm{mV}$ increments lasting $200 \mathrm{~ms}$ each (Misonou et al., 2004). The interpulse interval was $5 \mathrm{~s}$. Recordings of $I_{\mathrm{K}}$ were performed using an Axopatch 200B amplifier (Molecular Devices). Currents were digitized at $5 \mathrm{kHz}$ using an InstruTech ITC-16 interface and collected on a Macintosh G4 (Apple Computers) running AxoGraph 4.9.2 software (Molecular Devices). Neurons were bathed with extracellular recording solution $(\mathrm{pH}$ 7.4, osmolarity $\sim 320 \mathrm{mOsm}$ ) containing the following (in $\mathrm{mm}$ ): 135 $\mathrm{NaCl}, 5.4 \mathrm{KCl}, 1.8 \mathrm{CaCl}_{2}, 10$ glucose, 5 HEPES, and $0.1 \mathrm{TTX}$. Patch pipettes (3-5 M $\Omega$ ) were pulled from borosilicate glass $(0.86 \mathrm{~mm}$ inner diameter; Warner Instruments) and filled with internal solution ( $\mathrm{pH} 7.3$ using $\mathrm{KOH}$, osmolarity $\sim 300 \mathrm{mOsm}$ ) containing the following (in $\mathrm{mm}$ ): $140 \mathrm{KCl}, 1 \mathrm{CaCl}_{2}, 6 \mathrm{MgCl}_{2}$, 5 EGTA, $10 \mathrm{HEPES}$, and $4 \mathrm{NaATP}$. Access resistance was monitored throughout each recording, and cells that demonstrated access resistance below $25 \mathrm{M} \Omega$ that remained consistent were included in analyses. All currents were series and capacitance resistance compensated, and leak current was subtracted using a standard $P / n$ procedure. Average peak outward $\mathrm{K}^{+}$currents were measured between 100 and $110 \mathrm{~ms}$ into the pulse at each step potential and were converted to conductance $(G)$ using the following equation: $G=I /\left(V-E_{\mathrm{K}}\right)$. Normal- 
A

CTRL
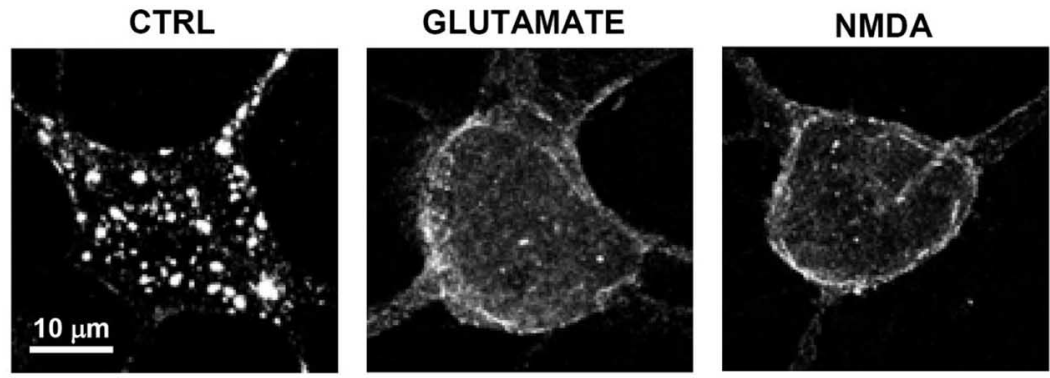

B

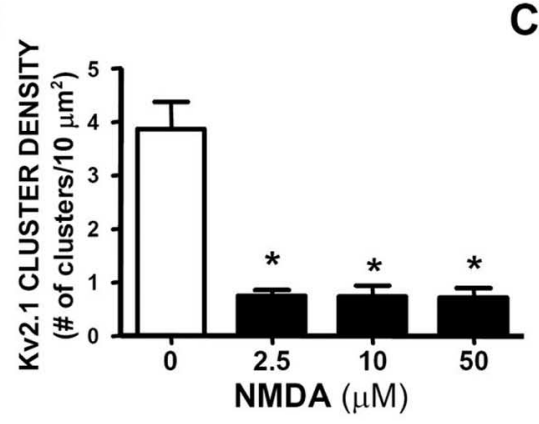

D
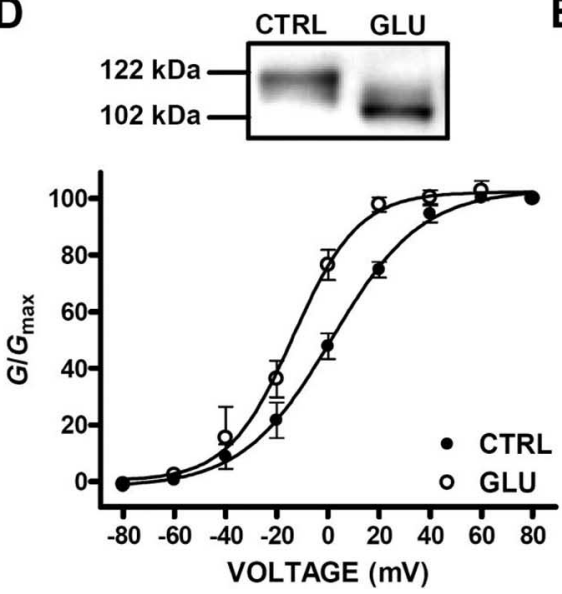

E
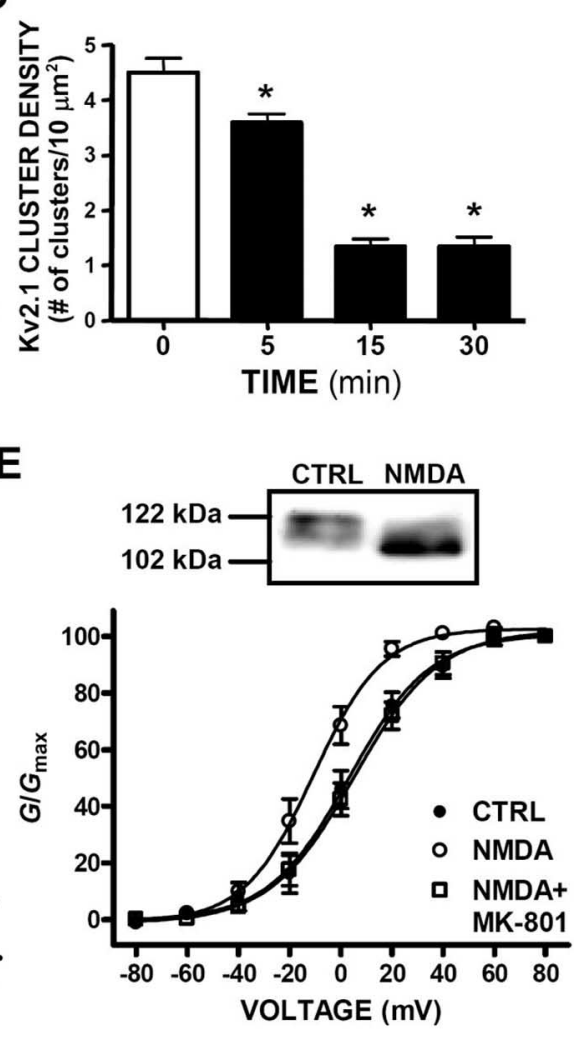

Figure 1. NMDA receptor modulation of Kv2.1 channels in primary hippocampal neurons. $\boldsymbol{A}$, Representative images of Kv2.1 unclustering after treatment $(20 \mathrm{~min})$ with glutamate $(10 \mu \mathrm{m})$ or NMDA $(10 \mu \mathrm{M})$. B, NMDA $(2.5-50 \mu \mathrm{M})$ treatment for $20 \mathrm{~min}$ significantly reduced Kv2.1 cluster density [ ${ }^{*} p<0.01$ vs 0 , ANOVA with Student-Newman-Keuls (SNK) test; $\left.n=10\right]$. C, Time course of $10 \mu \mathrm{m}$ NMDA-mediated dispersal of Kv2.1 cluster density ( ${ }^{*} p<0.01$ vs 0 min, ANOVA with SNK test; $\left.n=10\right)$. D, Bath application of glutamate $(10 \mu \mathrm{m})$ for 20 min dephosphorylated Kv2.1 channels and produced a hyperpolarizing leftward shift in the voltage activation curve for $I_{K}(n=4)$. $E$, Similar to glutamate, NMDA (10 $\mu \mathrm{m} ; 20 \mathrm{~min}$ ) also dephosphorylated Kv2.1 channels, and the NMDA-induced shift in the voltage activation curve for $I_{K}$ was blocked by MK- $801(n=4-5)$. Data are mean $\pm S E M$. CTRL, Control; GLU, glutamate.

ized $G$ was plotted against each test potential and fit to a single Boltzman equation, as described previously (Misonou et al., 2004, 2006). Measurement of $I_{\mathrm{K}}$ in slices from CA1 pyramidal neurons followed the aforementioned procedures except that currents were recorded in HEPES recording solution at $32^{\circ} \mathrm{C}$ with an EPC $9 / 3$ amplifier (HEKA Elektronik) using TIDA software version 5.05 (HEKA Elektronik) collected on a personal computer. Current density was measured by dividing average current between 100 and $110 \mathrm{~ms}$ of the $+80 \mathrm{mV}$ potential by the cell capacitance value. To measure NMDA receptor currents in CA1 pyramidal neurons, NMDA responses were isolated by the addition of 2,3-dihydroxy-6nitro-7-sulfonyl-benzo[f] quinoxaline (NBQX) $(25 \mu \mathrm{M})$, picrotoxin (300 $\mu \mathrm{M})$, and TTX $(1 \mu \mathrm{M})$ to $\mathrm{Mg}^{2+}$-free recording buffer, and NMDA or glutamate uptake inhibitors were locally applied for either 5 or $60 \mathrm{~s}$, respectively. Neurons were held at $-70 \mathrm{mV}$, and access resistance was monitored every $10 \mathrm{~s}$ by application of a $-10 \mathrm{mV}$ pulse for $10 \mathrm{~ms}$.
For measurement of NMDA-induced wholecell currents in cultured neurons, a multibarreled Warner Perfusion Fast-Step system $(\sim 8$ ms switching time; 2 psi; Warner Instruments) was used to apply agonist for $5 \mathrm{~s}$ by switching from the control barrel to the barrel containing NMDA and then back. Agonist-induced currents were recorded before and $10 \mathrm{~min}$ after MK-801 bath application, and the last $0.5 \mathrm{~s}$ of steady-state amplitude was measured using AxoGraph 4.9 software. Recordings of sEPSCs in neurons and slices were acquired over $5 \mathrm{~min}$ epochs without TTX and with $5 \mu \mathrm{M}$ lidocaine $\mathrm{N}$-ethyl bromide in the internal solution. Statistical analyses of whole-cell NMDA currents, cell capacitance values, and current density were performed using Prism version 4.03 (GraphPad Software).

Pentylenetetrazole-induced seizures. Adult male $\mathrm{C} 3 \mathrm{H} / \mathrm{He}$ mice (80-100 d of age; 25-28 g) obtained from Charles River Laboratories were used to examine the effect of seizure activity on Kv2.1 dephosphorylation. Animals were housed three to four per cage in an Association for Assessment and Accreditation of Laboratory Animal Care-accredited facility under a $12 \mathrm{~h}$ light/dark cycle (lights on at 6:00 A.M.) with ad libitum access to food and water. Mice were injected (intraperitoneally) with $35 \mathrm{mg} / \mathrm{kg}$ pentylenetetrazole (PTZ) or vehicle (saline) in a dose of $10 \mathrm{mg} / \mathrm{ml}$, and the number of myoclonic jerks was recorded for $20 \mathrm{~min}$ after injection. The mice were rapidly decapitated, the brain was removed, and a membrane fraction from bilateral excised hippocampi were prepared for analysis of Kv2.1 dephosphorylation following procedures described for neurons and slices. Additional untreated mice were placed in a $\mathrm{CO}_{2}$ inhalation chamber for $3 \mathrm{~min}$, and a hippocampal membrane fraction was prepared for blotting.

\section{Results}

NMDA receptors couple to modulation of Kv2.1 channels

Results from previous studies have shown that changes in Kv2.1 channel unclustering, dephosphorylation, and voltagedependent gating are initiated by $\mathrm{Ca}^{2+}$ influx during activation of glutamate receptors (Misonou et al., 2004, 2005b, 2006). Given that the changes in Kv2.1 by glutamate were partially prevented by NMDA receptor inhibition (Misonou et al., 2004, 2006) and that NMDA receptors play a critical role in many forms of activity-dependent synaptic plasticity, we examined the effect of direct activation of NMDA receptors on Kv2.1 channels. Bath application of glutamate $(10 \mu \mathrm{M})$ or NMDA (10 $\mu \mathrm{M})$ in the presence of TTX $(2 \mu \mathrm{M})$ unclustered somatodendritic Kv2.1 channels (Fig. 1A). NMDA, at concentrations as low as 2.5 $\mu \mathrm{M}$, rapidly reduced Kv2.1 cluster density (Fig. $1 B, C$ ). The glutamate-mediated change in Kv2.1 unclustering was associated with a significant shift $(1.55 \pm 2.20 \mathrm{mV}$ for controls and $-13.58 \pm 2.34 \mathrm{mV}$ for glutamate; $p<0.05)$ in the half-maximal conductance $\left(G_{1 / 2}\right)$ of neuronal $I_{\mathrm{K}}$ and dephosphorylation of Kv2.1 (Fig. $1 D$ ). Consistent with previous reports, alkaline phosphatase (AP) treatment also produced a hyperpolarizing shift in 
$G_{1 / 2}$ of neuronal $I_{\mathrm{K}}$ and dephosphorylated Kv2.1 (supplemental Fig. $1 A$, available at www.jneurosci.org as supplemental material). NMDA treatment produced a significant hyperpolarizing shift (approximately $-15 \mathrm{mV} ; p<0.05)$ in $G_{1 / 2}$ of neuronal $I_{\mathrm{K}}$ and dephosphorylated Kv2.1 (Fig. $1 E$ ) that was similar to that produced by treatment with glutamate or AP. The effects of NMDA on clustering and dephosphorylation were completely prevented by $100 \mu \mathrm{M}$ APV (data not shown) or $10 \mu \mathrm{M}$ MK-801 (Fig. $1 E$ ), respectively. Thus, these results directly demonstrate that NMDA receptors modulate Kv2.1 channels as was suggested previously using glutamate receptor antagonists.

Activation of synaptic NMDA receptors does not couple to modulation of Kv2.1 channels

As mentioned previously, Kv2.1 channels are thought to dynamically control excitability associated with periods of repetitive, high-frequency synaptic activity (Surmeier and Foehring, 2004; Misonou et al., 2005a). This has led to the suggestion that modulation of Kv2.1 by glutamate may represent a homeostatic feedback mechanism to attenuate burst firing after periods of sustained synaptic activity. One mechanism for this feedback regulation could be through hyperactivation of NMDA receptors that in turn engage Kv2.1 channels and dampen neuronal excitability. To examine this possibility, we used a cellular model of NMDA receptor hyperactivation and measured changes in Kv2.1 clustering, phosphorylation, and function. This model involves chronic exposure of cultures to ethanol that results in a compensatory increase in the expression of synaptic NMDA receptors without altering extrasynaptic NMDA receptors (Carpenter-Hyland et al., 2004; Qiang et al., 2007). As reported previously (Carpenter-Hyland et al., 2004; Hendricson et al., 2007), washout of the ethanolcontaining media after chronic ethanol exposure of either organotypic hippocampal slices or primary cortical neurons produced a robust increase in sEPSC (Fig. $2 A$ ). These experiments were performed in $\mathrm{Mg}^{2+}$-free buffer to maximize NMDA receptor activation and synaptic $\mathrm{Ca}^{2+}$ influx. Surprisingly, hyperactivation of synaptic NMDA receptors was not associated with changes in Kv2.1 dephosphorylation (Fig. $2 B$ ), voltage dependency for activation of $I_{\mathrm{K}}$ (Fig. 2C), cell capacitance, current density, or membrane-associated Kv2.1 protein levels (supplemental Fig. $1 B-D$, available at www.jneurosci.org as supplemental material). Chronic ethanol exposure before hyperactivation of synaptic NMDA receptors also did not affect these parameters (supplemental Fig. $1 B-D$, available at www.jneurosci.org as supplemental material). These data are in contrast to the potent

A
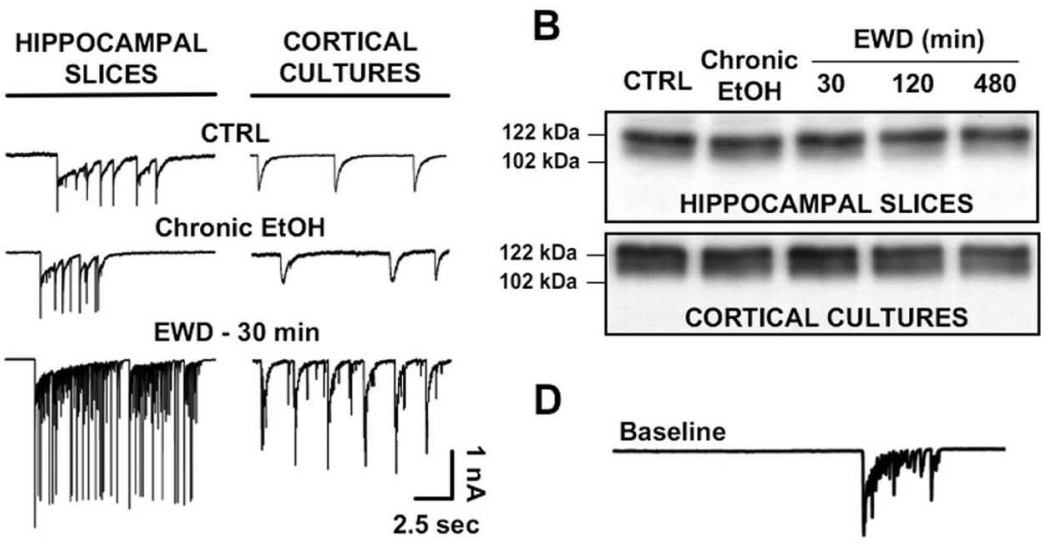

D

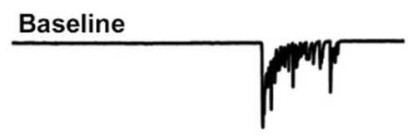

Bicuculline
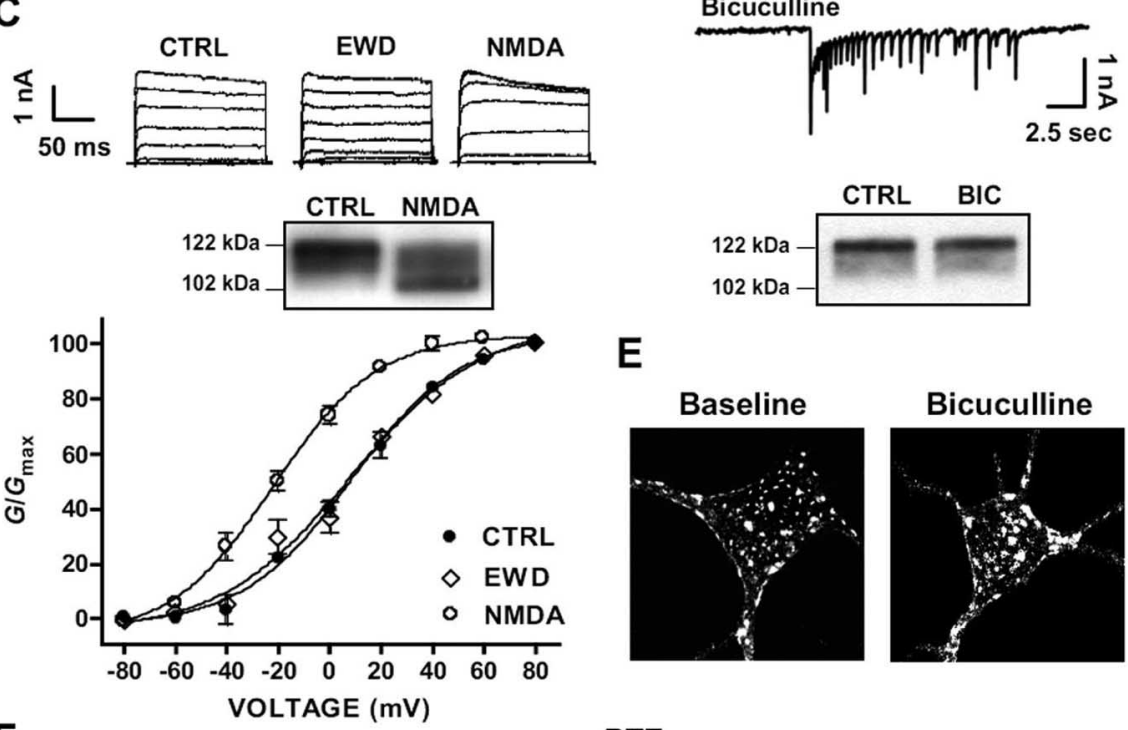

E

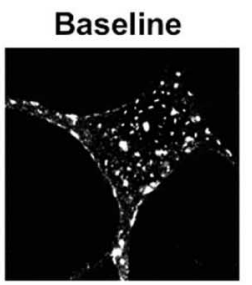
Bicuculline

PTZ

(\# of myoclonic jerks)

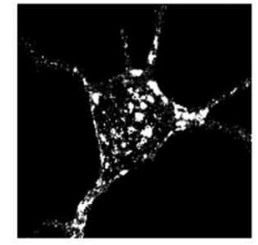

Figure 2. Increased synaptic activity does not couple to modulation of Kv2.1 channels. $\boldsymbol{A}$, Thirty minute withdrawal from chronic ethanol markedly increased sEPSC. $\boldsymbol{B}$, EWD does not dephosphorylate Kv2.1 channels ( $p>0.05$, ANOVA with SNK test; $n=3)$. C, Bath-applied NMDA, but not EWD hyperexcitability, produced a hyperpolarizing leftward shift in the voltage activation curve for $I_{K}$ in cortical cultures $(n=5-6)$. Inset shows representative blot of NMDA-mediated dephosphorylation of Kv2.1 in cortical neurons. D, Blocking inhibitory tone with bicuculline (50 $\mu \mathrm{m}, 30 \mathrm{~min}$ ) greatly increased sEPSC but did not affect Kv2.1 phosphorylation in hippocampal slices ( $p>0.05$, ANOVA; $n=4-5$ ). $\boldsymbol{E}$, Bicuculline did not affect Kv2.1 clustering in primary hippocampal cultures. $\boldsymbol{F}$, Brief $\mathrm{CO}_{2}$ inhalation, but not acute PTZ treatment, dephosphorylated Kv2.1 channels in hippocampus from adult C3H/He mice. CTRL, Control; Bic, bicuculline; SAL, saline.

shift in the $G_{1 / 2}(8.165 \pm 2.274 \mathrm{mV}$ for controls, $8.332 \pm 3.695$ $\mathrm{mV}$ for ethanol withdrawal (EWD), and $-21.6 \pm 2.265 \mathrm{mV}$ for glutamate; $p<0.01$ ) of neuronal $I_{\mathrm{K}}$ and reduced phosphorylation of Kv2.1 in cortical neurons after acute treatment with $10 \mu \mathrm{M}$ NMDA (Fig. 2C). Because chronic ethanol can affect the expression and function of other proteins in addition to increasing expression of synaptic NMDA receptors, we used a different method of inducing hyperactivation of synaptic NMDA receptors. Bath application of bicuculline (in $\mathrm{Mg}^{2+}$-free buffer) to remove inhibitory tone and facilitate synaptic activity also did not affect Kv2.1 phosphorylation (Fig. 2D) or clustering (Fig. 2 E). In addition to these in vitro hyperactivity models, we examined the 
A

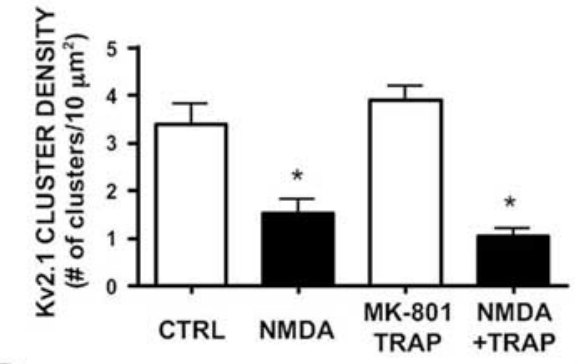

B
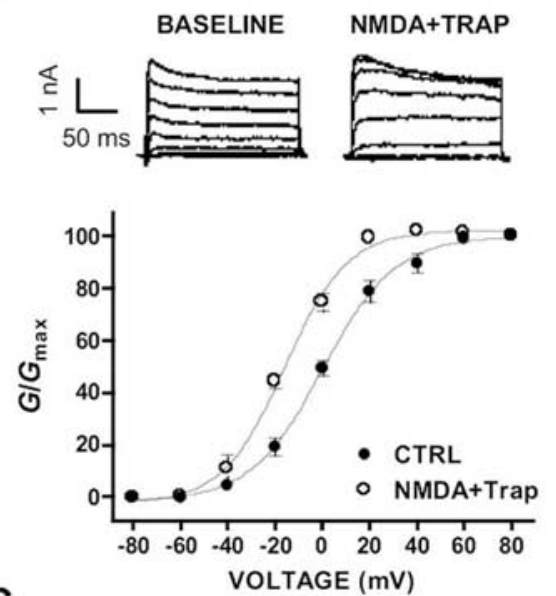

C

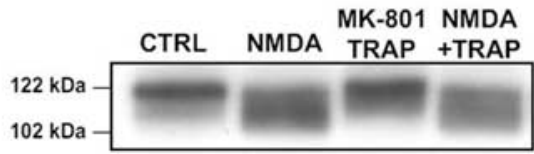

D

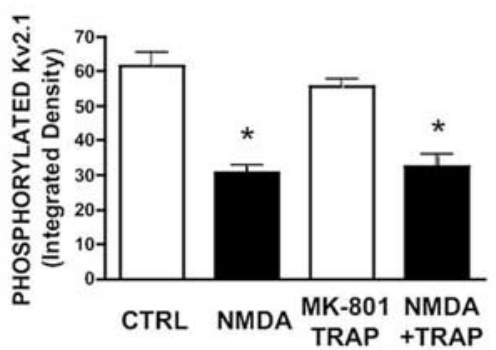

E

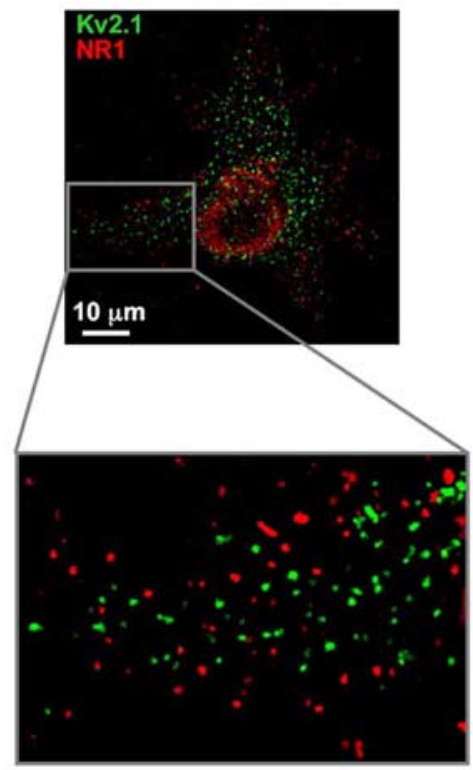

Figure 3. Extrasynaptic NMDA receptor modulation of Kv2.1 channels in primary hippocampal neurons. $\boldsymbol{A}$, After MK-801 trapping of synaptic NMDA receptors, bath application of $10 \mu \mathrm{M} \mathrm{NMDA} \mathrm{(20} \mathrm{min)} \mathrm{induced} \mathrm{unclustering} \mathrm{of} \mathrm{Kv2.1} \mathrm{channels}\left({ }^{*} p<\right.$ 0.01 vs control, ANOVA with SNK test; $n=10$ ). $\boldsymbol{B}$, The NMDA-induced hyperpolarizing shift in the voltage dependency for $I_{K}$ activation was not prevented by selective MK-801 block (trap) of synaptic NMDA receptors $(n=4-5)$. C, D, NMDA-mediated activation of extrasynaptic NMDA receptors dephosphorylated Kv2.1 channels ( ${ }^{*} p<0.001$ vs control, ANOVA with SNK test; $n=$ 5). $\boldsymbol{E}$, Representative image of Kv2.1 and NR1 clusters demonstrating lack of colocalization. CTRL, Control.

effect of seizure activity on Kv2.1 dephosphorylation in an in vivo model. Consistent with our in vitro data, PTZ-induced seizure activity did not dephosphorylate Kv2.1 channels; however, brief exposure ( $3 \mathrm{~min}$ ) of adult $\mathrm{C} 3 \mathrm{H} / \mathrm{He}$ mice to $\mathrm{CO}_{2}$ in an inhalation chamber markedly dephosphorylated Kv2.1 channels (Fig. 2 F). Thus, contrary to the initial hypothesis, these data indicate that sustained activation of synaptic NMDA receptors does not alter Kv2.1 channel clustering, phosphorylation, or function.

\section{Modulation of Kv2.1 is selectively coupled to extrasynaptic NMDA receptors}

Given the results demonstrating that Kv2.1 channel function is altered by bath-applied NMDA but not by activation of synaptic NMDA receptors, we next examined the possibility that NMDA receptor modulation of Kv2.1 is coupled to activation of extrasynaptic NMDA receptors. To test this hypothesis, we isolated extrasynaptic receptors by using the MK-801 trapping technique to selectively inactivate synaptic NMDA receptors (Lu et al., 2001; Tovar and Westbrook, 2002). After MK-801 trapping, there was, as expected, a large $(\sim 50 \%)$ reduction in the whole-cell NMDA current during local application of NMDA (supplemental Fig. $2 A, B$, available at www.jneurosci.org as supplemental material). Under these conditions, NMDA markedly reduced Kv2.1 cluster density (Fig. 3A). Moreover, selectively activating extrasynaptic NMDA receptors produced a significant hyperpolarizing shift (approximately $-16 \mathrm{mV} ; p<.01$ ) in the $G_{1 / 2}$ of neuronal $I_{\mathrm{K}}$ (Fig. $3 B$ ) and dephosphorylated Kv2.1 channels (Fig. $3 C, D)$. Separately, the NMDA receptor antagonists Ro25-6981 [R- $(R, S)-\alpha-(4-$ hydroxyphenyl)- $\beta$-methyl-4-(phenylmethyl)-1-piperidine propranol] and NVP-AAM077 ([(R)-[(S)-1-(4-bromophenyl)-ethylamino]-(2,3-dioxo-1,2,3,4tetrahydro-quinoxalin-5-yl)-methyl]phosphonic acid) produced partial attenuation of extrasynaptic NMDA receptor-mediated dephosphorylation of Kv2.1, but, in combination, they completely prevented this effect (supplemental Fig. 2C, available at www.jneurosci.org as supplemental material). MK801 block of synaptic NMDA receptors did not alter the voltage dependency for activation of $I_{\mathrm{K}}$ or cause hyperphosphorylation of Kv2.1 (Fig. $3 B, C$ ). These results clearly demonstrate that modulation of Kv2.1 channels is selectively coupled to extrasynaptic but not synaptic NMDA receptors. Using automated colocalization analyses, we also observed that Kv2.1 puncta did not colocalize with NR1 (Pearson's coefficient, $-0.09 \pm$ 0.04 ; percentage colocalized, $9.1 \pm 2.5$; $n=5$ ) (Fig. $3 E$ ) or PSD-95 (data not shown), suggesting that clusters of Kv2.1 channels reside outside of glutamatergic synapses.

\section{Glutamate uptake controls NMDA receptor modulation of $\mathrm{Kv} 2.1$}

Sustained synaptic activity such as that produced in hyperexcitability models may allow glutamate to escape or spillover from the synapse. Such increases in extrasynaptic glutamate could in turn activate extrasynaptic NMDA receptors that modulate Kv2.1 channels. However, because this did not appear to be the case, we tested whether excitatory amino acid transporters (EAATs) regulate activation of extrasynaptic NMDA receptors that are linked to modulation of Kv2.1 channels using organotypic hippocampal slices that maintain a normal glia-neuronal component (Hailer et al., 1996; Benediktsson et al., 2005; Haber et al., 2006). Recent evidence suggests that EAATs tightly maintain ambient extracellular glutamate concentrations at $\sim 25 \mathrm{~nm}$ (Herman and Jahr, 2007). Similar to observations in primary neurons, bath application of NMDA to organotypic hippocampal slices also dephosphorylated and unclustered Kv2.1 channels (Fig. 4A,D), and, consistent with a previous report using glutamate (Misonou et al., 2004), this effect was reversible (Fig. $4 B, C$ ). In contrast to a previous study using glutamate (Misonou et al., 2004), inhibition of calcineurin activation did not prevent NMDA-mediated dephosphorylation of Kv2.1. The calcineurin inhibitor FK520 $(0.01-5 \mu \mathrm{M})$ partially attenuated Kv2.1 dephosphorylation only at high concentrations (supplemental Fig. 2D, available at www.jneurosci.org as supplemental material), and we did not observe any effect on NMDA dephos- 

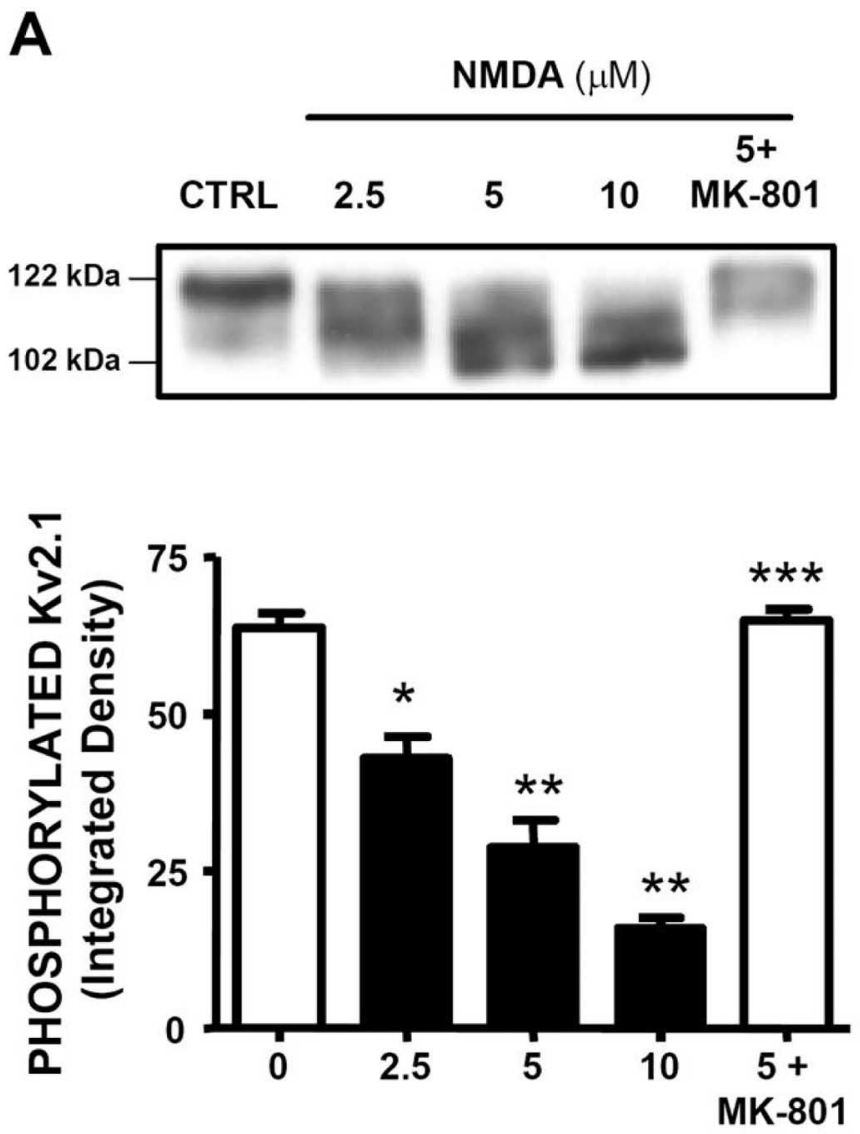

NMDA $(\mu \mathrm{M})$

B

\section{TIME AFTER NMDA (hr)}

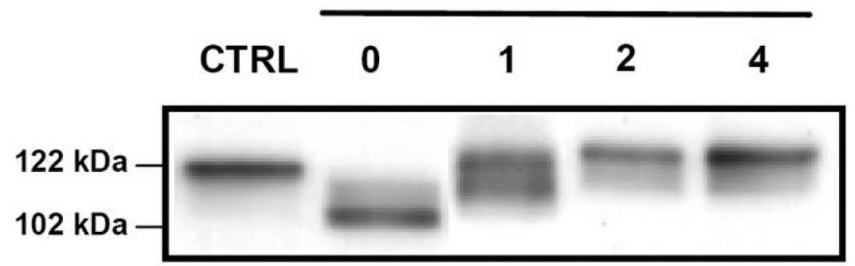

C

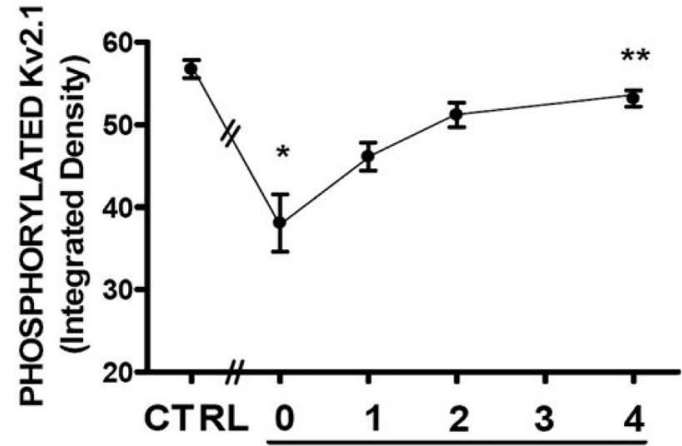

D

\section{CTRL}

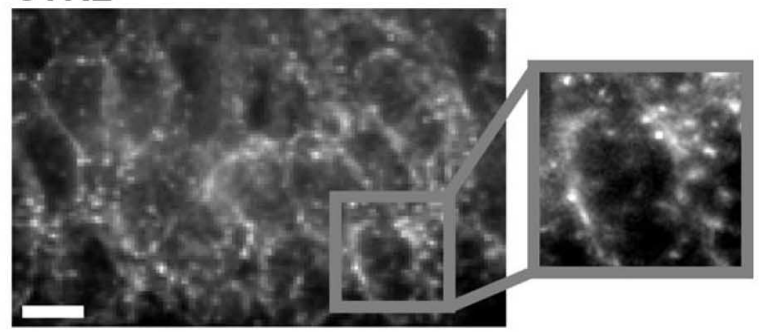

NMDA

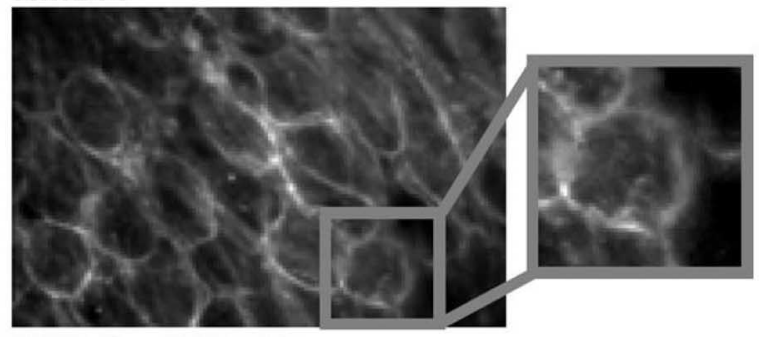

NMDA + MK-801

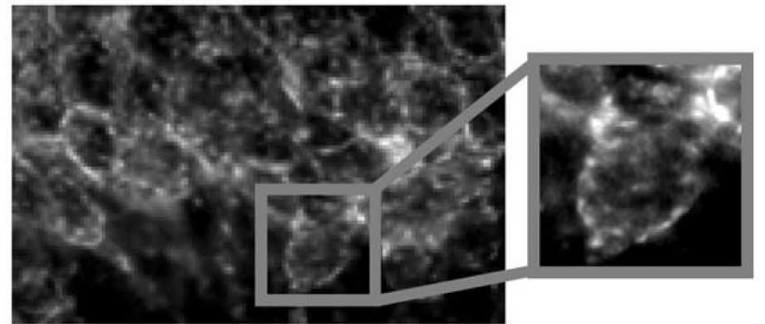

Figure 4. NMDA-induced dephosphorylation of Kv2.1 in organotypic hippocampal slices is reversible. $A$, Bath application of NMDA (2.5-10 $\mu$ M; 30 min) significantly reduced phosphorylated levels of Kv2.1. MK-801 blocked dephosphorylation of Kv2.1 by $5 \mu$ M NMDA $\left({ }^{*} p<0.05\right.$ vs control, ${ }^{* *} p<0.01$ vs control, ${ }^{* * *} p<0.01$ vs $5 \mu$ m NMDA, ANOVA with SNK test; $\left.n=4\right)$. $B, C$, Time course of Kv2.1 rephosphorylation after $10 \mu \mathrm{m}$ NMDA treatment. ( ${ }^{*} p<0.01$ vs control, ${ }^{* *} p<0.01$ vs time 0 , ANOVA with SNK test; $n=4$ ). $\boldsymbol{D}$, Representative images of $10 \mu \mathrm{m}$ NMDA-mediated unclustering of Kv2.1 channels in hippocampal slices. As shown, unclustering of Kv2.1 by NMDA treatment (20 min) was completely prevented by MK-801 (10 $\mu \mathrm{M}$ ). Scale bar, $10 \mu \mathrm{m}$. CTRL, Control.

phorylation of Kv2.1 using the calcineurin inhibitor cypermethrin $(0.01-5 \mu \mathrm{M})$ (data not shown). Kv2.1 channels are phosphorylated at multiple sites (Park et al., 2006), and these data suggest that extrasynaptic NMDA receptors may dephosphorylate Kv2.1 channels at calcineurin-independent dephosphorylation sites.

Inhibition of glutamate uptake with the nonselective, nontransportable EAAT inhibitor DL-threo- $\beta$-benzyloxyaspartic acid (TBOA) dephosphorylated Kv2.1 even in the presence of TTX, and this effect was completely prevented by coincubation of TBOA with MK-801 (Fig. 5A,B). EAAT1-EAAT4 isoforms are expressed in hippocampus with EAAT1/2 being primarily localized to astroglia (Bridges and Esslinger, 2005). Astrocytic EAAT2 is suggested to account for $\sim 80 \%$ of glutamate uptake in hippocampus (Danbolt, 2001). Therefore, we next examined the effects of subtype-selective EAAT inhibitors on NMDA receptor modulation of Kv2.1 dephosphorylation. Treatment of slices with EAAT2 inhibitors dihydrokainic acid (DHK) (Fig. 5A,B) or WAY-213613 [N(4)-[4-(2-bromo-4, 5-difluorophenoxy)phenyl]L-asparagine] (supplemental Fig. 3, available at www. jneurosci.org as supplemental material) in the presence of TTX significantly reduced Kv2.1 phosphorylation levels. The effect of DHK on Kv2.1 dephosphorylation was prevented by MK-801 but not by CNQX. L-Serine-O-sulfate (SOS), an EAAT1/3 inhibitor, also significantly reduced phosphorylation of Kv2.1 channels (Fig. $5 A, B$ ). Recent evidence has demonstrated that variable de- 
A
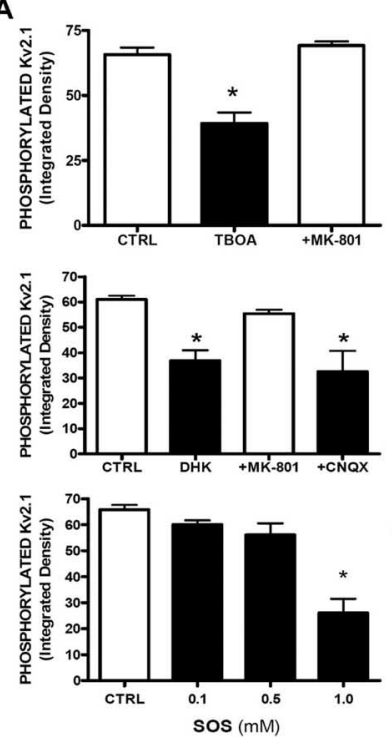

D

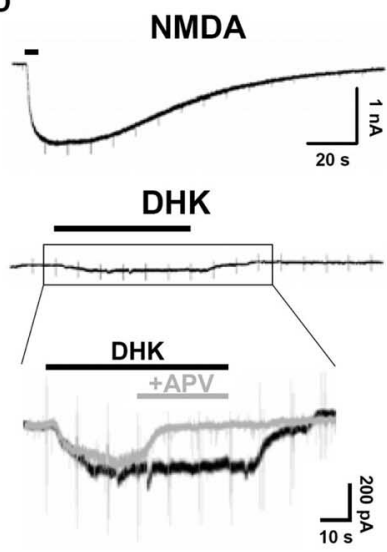

B
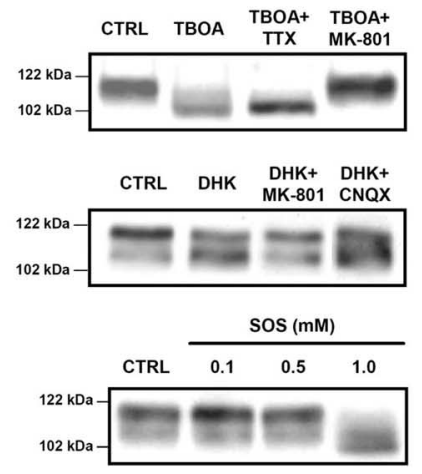

C

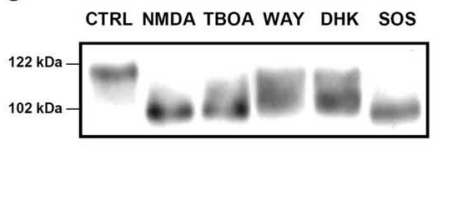

TBOA
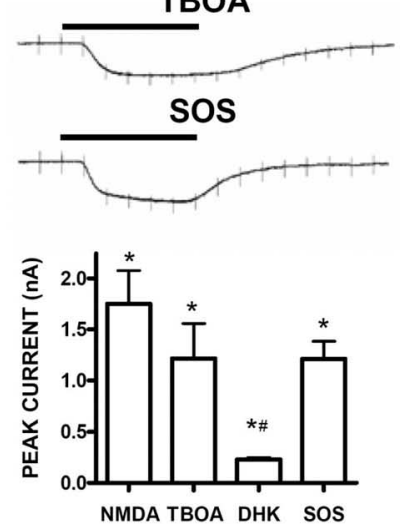

Figure 5. EAATs control extrasynaptic NMDA receptor-mediated dephosphorylation of Kv2.1 channels. A, TBOA $(200 \mu \mathrm{M})$, DHK ( $500 \mu \mathrm{M})$, or SOS (1 mM) treatment for 30 min dephosphorylated Kv2.1 in the presence of $2 \mu \mathrm{M}$ TTX in hippocampal slices ( ${ }^{*} p<0.05$ vs control, ANOVA with SNK test; $n=3-6$ ). $\boldsymbol{B}$, Representative immunoblot illustrating dephosphorylation of Kv2.1 induced by EAAT inhibitors. C, Comparison of graded Kv2.1 dephosphorylation induced by NMDA and EAAT inhibitors. $\boldsymbol{D}$, Isolated NMDA receptor currents evoked by local perfusion of NMDA or EAAT inhibitors. NMDA receptor-mediated currents induced by DHK were blocked by $50 \mu \mathrm{M}$ APV coexposure $(n=4)$. Average amplitude of peak currents in CA1 neurons locally perfused with NMDA or EAAT inhibitors ( ${ }^{\#} p<0.05$ vs NMDA, TBOA, or SOS, ANOVA with SNK test; $n=4-7)$. One-sample $t$ tests indicated that amplitude of peak current in each treatment was significantly different from baseline $\left({ }^{*} p<0.05\right)$. CTRL, Control.

phosphorylation produced graded activity-dependent regulation of Kv2.1 channel gating (Misonou et al., 2006). A direct comparison of Kv2.1 dephosphorylation by NMDA and EAAT inhibitors demonstrated that NMDA, TBOA, or SOS produced bulk dephosphorylation, whereas EAAT2 inhibitors DHK or WAY213613 produced partial dephosphorylation of the major form of phosphorylated Kv2.1 (Fig. 5C) (supplemental Fig. 3, available at www.jneurosci.org as supplemental material). These observations indicate that EAATs are important in regulating the functional coupling between extrasynaptic NMDA receptors and Kv2.1 channels.

To confirm that EAAT inhibitors were indeed activating NMDA receptors, isolated NMDA receptor currents were recorded in CA1 pyramidal neurons in the presence of TTX $(2 \mu \mathrm{M})$, picrotoxin $(100 \mu \mathrm{M})$, and NBQX $(25 \mu \mathrm{M})$ in $\mathrm{Mg}^{2+}$-free recording buffer. As expected, brief local NMDA $(10 \mu \mathrm{M})$ perfusion via a

flow pipette produced large inward currents $(1.75 \pm 0.32 \mathrm{nA} ; n=$ 5) (Fig. 5D). Perfusion of TBOA $(200 \mu \mathrm{M})$ or SOS $(1 \mathrm{~mm})$ for 1 min also greatly increased isolated NMDA receptor currents (TBOA, $1.22 \pm 0.34 \mathrm{nA}, n=3$; SOS, $1.21 \pm 0.17 \mathrm{nA}, n=4)$, whereas DHK $(500 \mu \mathrm{M})$ or WAY-213613 $(50 \mu \mathrm{M})$ produced currents of significantly smaller peak amplitude $(0.23 \pm 0.02 \mathrm{nA} ; n=$ 7) (Fig. 5D) (supplemental Fig. 3, available at www.jneurosci.org as supplemental material). Perfusion of $50 \mu \mathrm{M}$ APV with DHK blocked the increase in NMDA receptor currents in all cells tested $(n=4)$ (Fig. 5D). These data suggest that EAATs control extrasynaptic NMDA receptor dephosphorylation of Kv2.1 by tightly regulating levels of ambient nonsynaptic glutamate.

\section{Discussion}

Voltage-gated $\mathrm{K}^{+}$channels play a critical role in regulating neuronal excitability, and recent evidence suggests that Kv2.1 channels are particularly important in controlling action potential generation associated with periods of repetitive, high-frequency firing (Du et al., 2000; Misonou et al., 2004, 2006). Of particular interest in regards to potential mechanisms of homeostatic plasticity are observations that glutamatergic neurotransmission alters the functional properties and localization of Kv2.1 channels. In the present study, we demonstrated that NMDA receptor modulation of Kv2.1 channels is coupled to extrasynaptic but not synaptic NMDA receptors. We further demonstrated that the EAATs tightly regulate the activity of the extrasynaptic pool of NMDA receptors that couples to modulation of Kv2.1. This suggests a previously unknown role for EAATs in modulating neuronal activity and burst firing through regulation of the activity of extrasynaptic NMDA receptors. Under normal conditions, the high efficiency of the EAATs appears to prevent activation of extrasynaptic NMDA receptors in the somatodendritic domain in which Kv2.1 channels are localized.

In agreement with previous studies using exogenously applied glutamate, we observed that bath application of NMDA potently and rapidly unclustered and dephosphorylated Kv2.1 channels and produced a hyperpolarizing shift in the voltage-dependent activation of neuronal $I_{\mathrm{K}}$. Previous studies have shown that hyperactivity associated with seizures or $\mathrm{KCl}$-induced membrane depolarization causes dephosphorylation and unclustering of Kv2.1 channels (Misonou et al., 2004). In light of this observation and the suggestion that Kv2.1 channels control repetitive burst firing, we hypothesized that sustained activation of synaptic NMDA receptors would also engage Kv2.1 as a potential homeostatic feedback mechanism to attenuate neuronal excitability. To test this hypothesis, we used a chronic ethanol exposure and withdrawal model of hyperexcitability that is characterized by upregulation and enhanced localization of NMDA receptors selectively at the postsynaptic density (Carpenter-Hyland et al., 2004; Hendricson et al., 2007; Qiang et al., 2007). As a second model of hyperactivation of synaptic NMDA receptors, we used bath application of the $\mathrm{GABA}_{\mathrm{A}}$ receptor antagonist bicuculline that is known to produce burst firing and is commonly used to model epileptic events in vitro (Gulyás-Kovács et al., 2002). Contrary to our original hypothesis, exposure to bicuculline or withdrawal from chronic ethanol exposure, both of which greatly enhanced synaptic NMDA currents, did not induce dephosphorylation or unclustering of Kv2.1 channels or cause a hyperpolarizing shift in the voltage activation curve of neuronal $I_{\mathrm{K}}$. Furthermore, inhibition of synaptic NMDA receptor activity using MK-801 trapping did not produce a depolarizing shift in $I_{\mathrm{K}}$ activation or a hyperphosphorylation of Kv2.1. Finally, moderate seizure activity induced by $20 \mathrm{~min}$ PTZ treatment in adult mice 
did not dephosphorylate hippocampal Kv2.1 channels. Recent studies have demonstrated that seizures induced by injection of kainate dephosphorylated and unclustered Kv2.1 channels in cortex and subiculum (Misonou et al., 2004, 2006). The reason for the discrepancy between our findings and those reported by Misonou et al. is unclear but may relate to seizure-associate hypoxia or to the duration and severity of seizure activity. Nevertheless, together these data suggest that synaptic NMDA receptors do not play a major role in regulating Kv2.1 channels.

In contrast to the lack of coupling between synaptic NMDA receptors and modulation of Kv2.1, the properties of these channels were rapidly altered by bath application of NMDA, and this effect persisted after MK801 trapping of synaptic NMDA receptors. These results suggest that extrasynaptic but not synaptic NMDA receptors modulate Kv2.1 in response to elevated glutamate concentrations. The coupling of extrasynaptic NMDA receptors to altered Kv2.1 function did not show NMDA receptor subunit specificity as a highly selective NR2B antagonist and a less selective NR2A antagonist both significantly antagonized the extrasynaptic NMDA receptor-mediated effect on Kv2.1. We also demonstrated that Kv2.1 channels do not colocalize with the obligatory NR1 subunit of NMDA receptors or the postsynaptic density scaffolding protein PSD-95, suggesting that somatodendritic clusters of Kv2.1 channels reside outside of glutamatergic synapses in hippocampal neurons.

Although enhanced activity of synaptic NMDA receptors did not alter Kv2.1 channels, blocking glutamate uptake with the nontransportable EAAT1-EAAT4 inhibitor TBOA, the EAAT1/3 inhibitor SOS, or the selective EAAT2 inhibitors DHK or WAY213613 dephosphorylated Kv2.1. These findings are consistent with evidence for a direct link between inhibition of EAATs and activation of extrasynaptic NMDA receptors (Cattani et al., 2007; Le Meur et al., 2007) and provide additional evidence of the role of extrasynaptic NMDA receptors in modulating Kv2.1. However, although these studies clearly indicate that EAATs may critically regulate activation of extrasynaptic NMDA receptors, they do not address the origin of the glutamate that activates this pathway. One potential source is spillover of synaptic glutamate into the extrasynaptic compartment. In support of this idea, brief high-frequency stimulation of synaptic activity can increase extracellular levels of glutamate in sufficient amounts to activate extrasynaptic NMDA receptors in cerebellum (Clark and CullCandy, 2002). However, we did not observe changes in Kv2.1 in response to three models of hyperexcitability. More importantly, our observations demonstrating dephosphorylation of Kv2.1 and activation of isolated NMDA receptor currents by EAAT inhibitors in the presence of TTX suggests that the source of glutamate that activates extrasynaptic NMDA receptors appears to be nonsynaptic. Indeed, evidence suggests that passive diffusion of glutamate across lipid membranes and glutamate release from astrocytes contributes to ambient glutamate (Cavelier and Attwell, 2005), and studies have demonstrated that EAATs tightly compensate for the rapid accumulation of ambient glutamate (Jabaudon et al., 1999; Cavelier and Attwell, 2005; Herman and Jahr, 2007). Consistent with previous reports, we demonstrated that EAAT inhibitors increased extracellular glutamate in sufficient concentrations to activate NMDA receptors. Together, these observations indicate that the EAATs are highly efficient in removing ambient glutamate to levels below that need to activate extrasynaptic NMDA receptors that couple to modulation of Kv2.1. These data further suggest a role for Kv2.1 in modulating intrinsic excitability during periods of elevated ambient glutamate or decreased uptake of glutamate by EAATs.
We demonstrated that inhibition of EAAT2 produces a graded dephosphorylation of Kv2.1 and a relatively small increase in isolated NMDA receptor currents when compared with bulk dephosphorylation and large currents induced by TBOA or SOS. It should be noted that the EAAT1/3 inhibitor SOS produced significant dephosphorylation of Kv2.1 at concentrations that would also block glutamate uptake by EAAT2 (Vandenberg et al., 1998; Apricó et al., 2001). Interestingly, somatodendritic clusters of Kv2.1 localize in close apposition to astrocytic processes (Du et al., 1998), and astrocytic EAAT2 is thought to control $\sim 80 \%$ of glutamate uptake in hippocampus (Danbolt, 2001). Recent evidence has linked activation of extrasynaptic NMDA receptors with astrocytic gliotransmission in hippocampus and nucleus accumbens (Fellin et al., 2004; D’Ascenzo et al., 2007; Le Meur et al., 2007). It is tempting to speculate that EAAT2 regulates glutamate in the microenvironment of the extrasynaptic NMDA receptors that couple to modulation of Kv2.1 dephosphorylation. It is also possible that EAAT2 inhibition produced a partial dephosphorylation of Kv2.1 attributable to compensation of glutamate uptake by EAAT1/3, and the graded response of Kv2.1 dephosphorylation by EAAT inhibitors may be indicative of increasing concentrations of ambient glutamate.

In conclusion, our results reveal that NMDA receptor modulation of Kv2.1 is controlled exclusively by NMDA receptors that are located outside the synapse. Activation of these extrasynaptic NMDA receptors is tightly controlled by the activity of EAATs. Our observation that glial EAATs may regulate Kv2.1 dephosphorylation together with the known juxtaposition of astroglia with somatodendritic Kv2.1 channels supports a novel mechanism for glial EAATs in regulating neuronal excitability and plasticity through dynamic control of extrasynaptic NMDA receptor modulation of Kv2.1 channels.

\section{References}

Apricó K, Beart PM, Lawrence AJ, Crawford D, O'Shea RD (2001) $\left[{ }^{3} \mathrm{H}\right](2 S, 4 R)-4-$ Methylglutamate: a novel ligand for the characterization of glutamate transporters. J Neurochem 77:1218-1225.

Benediktsson AM, Schachtele SJ, Green SH, Dailey ME (2005) Ballistic labeling and dynamic imaging of astrocytes in organotypic hippocampal slice cultures. J Neurosci Methods 141:41-53.

Bridges RJ, Esslinger CS (2005) The excitatory amino acid transporters: pharmacological insights on substrate and inhibitor specificity of the EAAT subtypes. Pharmacol Ther 107:271-285.

Carpenter-Hyland EP, Chandler LJ (2006) Homeostatic plasticity during alcohol exposure promotes enlargement of dendritic spines. Eur J Neurosci 24:3496-3506.

Carpenter-Hyland EP, Woodward JJ, Chandler LJ (2004) Chronic ethanol induces synaptic but not extrasynaptic targeting of NMDA receptors. J Neurosci 24:7859-7868.

Cattani AA, Bonfardin VD, Represa A, Ben-Ari Y, Aniksztejn L (2007) Generation of slow network oscillations in the developing rat hippocampus after blockade of glutamate uptake. J Neurophysiol 98:2324-2336.

Cavelier P, Attwell D (2005) Tonic release of glutamate by a DIDS-sensitive mechanism in rat hippocampal slices. J Physiol 564:397-410.

Chandler LJ, Sutton G, Norwood D, Sumners C, Crews FT (1997) Chronic ethanol increases $N$-methyl-D-aspartate-stimulated nitric oxide formation but not receptor density in cultured cortical neurons. Mol Pharmacol 51:733-740.

Clark BA, Cull-Candy SG (2002) Activity-dependent recruitment of extrasynaptic NMDA receptor activation at an AMPA receptor-only synapse. J Neurosci 22:4428-4436.

Costes SV, Daelemans D, Cho EH, Dobbin Z, Pavlakis G, Lockett S (2004) Automatic and quantitative measurement of protein-protein colocalization in live cells. Biophys J 86:3993-4003.

D’Ascenzo M, Fellin T, Terunuma M, Revilla-Sanchez R, Meaney DF, Auberson YP, Moss SJ, Haydon PG (2007) mGluR5 stimulates gliotransmission in the nucleus accumbens. Proc Natl Acad Sci U S A 104:1995-2000. 
Danbolt NC (2001) Glutamate uptake. Prog Neurobiol 65:1-105.

Du J, Tao-Cheng JH, Zerfas P, McBain CJ (1998) The $\mathrm{K}^{+}$channel, Kv2.1, is apposed to astrocytic processes and is associated with inhibitory postsynaptic membranes in hippocampal and cortical principal neurons and inhibitory interneurons. Neuroscience 84:37-48.

Du J, Haak LL, Phillips-Tansey E, Russell JT, McBain CJ (2000) Frequencydependent regulation of rat hippocampal somato-dendritic excitability by the $\mathrm{K}^{+}$channel subunit Kv2.1. J Physiol 522:19-31.

Fellin T, Pascual O, Gobbo S, Pozzan T, Haydon PG, Carmignoto G (2004) Neuronal synchrony mediated by astrocytic glutamate through activation of extrasynaptic NMDA receptors. Neuron 43:729-743.

Gulyás-Kovács A, Dóczi J, Tarnawa I, Détári L, Banczerowski-Pelyhe I, Világi I (2002) Comparison of spontaneous and evoked epileptiform activity in three in vitro epilepsy models. Brain Res 945:174-180.

Haber M, Zhou L, Murai KK (2006) Cooperative astrocyte and dendritic spine dynamics at hippocampal excitatory synapses. J Neurosci 26:8881-8891.

Hailer NP, Jarhult JD, Nitsch R (1996) Resting microglial cells in vitro: analysis of morphology and adhesion molecule expression in organotypic hippocampal slice cultures. Glia 18:319-331.

Hendricson AW, Maldve RE, Salinas AG, Theile JW, Zhang TA, Diaz LM, Morrisett RA (2007) Aberrant synaptic activation of N-methyl-Daspartate receptors underlies ethanol withdrawal hyperexcitability. J Pharmacol Exp Ther 321:60-72.

Herman MA, Jahr CE (2007) Extracellular glutamate concentrations in hippocampal slice. J Neurosci 27:9736-9741.

Jabaudon D, Shimamoto K, Yasuda-Kamatani Y, Scanziani M, Gähwiler BH, Gerber U (1999) Inhibition of uptake unmasks rapid extracellular turnover of glutamate of nonvesicular origin. Proc Natl Acad Sci U S A 96:8733-8738.

Le Meur K, Galante M, Angulo MC, Audinat E (2007) Tonic activation of NMDA receptors by ambient glutamate of non-synaptic origin in the rat hippocampus. J Physiol 580:373-383.

Lu W, Man H, Ju W, Trimble WS, MacDonald JF, Wang YT (2001) Activation of synaptic NMDA receptors induces membrane insertion of new AMPA receptors and LTP in cultured hippocampal neurons. Neuron 29:243-254.

Marvizón JC, Pérez OA, Song B, Chen W, Bunnett NW, Grady EF, Todd AJ (2007) Calcitonin receptor-like receptor and receptor activity modifying protein 1 in the rat dorsal horn: localization in glutamatergic presynaptic terminals containing opioids and adrenergic alpha2C receptors. Neuroscience 148:250-265.

Misonou H, Mohapatra DP, Park EW, Leung V, Zhen D, Misonou K, Anderson AE, Trimmer JS (2004) Regulation of ion channel localization and phosphorylation by neuronal activity. Nat Neurosci 7:711-718.

Misonou H, Mohapatra DP, Trimmer JS (2005a) Kv2.1: a voltage-gated k+ channel critical to dynamic control of neuronal excitability. Neurotoxicology 26:743-752.

Misonou H, Mohapatra DP, Menegola M, Trimmer JS (2005b) Calciumand metabolic state-dependent modulation of the voltage-dependent Kv2.1 channel regulates neuronal excitability in response to ischemia. J Neurosci 25:11184-11193.

Misonou H, Menegola M, Mohapatra DP, Guy LK, Park KS, Trimmer JS (2006) Bidirectional activity-dependent regulation of neuronal ion channel phosphorylation. J Neurosci 26:13505-13514.

Mulholland PJ, Self RL, Harris BR, Little HJ, Littleton JM, Prendergast MA (2005) Corticosterone increases damage and cytosolic calcium accumulation associated with ethanol withdrawal in rat hippocampal slice cultures. Alcohol Clin Exp Res 29:871-881.

Mulholland PJ, Luong NT, Woodward JJ, Chandler LJ (2008) Brain-derived neurotrophic factor activation of extracellular signal-regulated kinase is autonomous from the dominant extrasynaptic NMDA receptor extracellular signal-regulated kinase shutoff pathway. Neuroscience 151:419-427.

Murakoshi H, Trimmer JS (1999) Identification of the Kv2.1 $\mathrm{K}^{+}$channel as a major component of the delayed rectifier $\mathrm{K}^{+}$current in rat hippocampal neurons. J Neurosci 19:1728-1735.

Park KS, Mohapatra DP, Misonou H, Trimmer JS (2006) Graded regulation of the Kv2.1 potassium channel by variable phosphorylation. Science 313:976-979.

Qiang M, Denny AD, Ticku MK (2007) Chronic intermittent ethanol treatment selectively alters $N$-methyl-D-aspartate receptor subunit surface expression in cultured cortical neurons. Mol Pharmacol 72:95-102.

Surmeier DJ, Foehring R (2004) A mechanism for homeostatic plasticity. Nat Neurosci 7:691-692.

Tovar KR, Westbrook GL (2002) Mobile NMDA receptors at hippocampal synapses. Neuron 34:255-264.

Vandenberg RJ, Mitrovic AD, Johnston GA (1998) Serine-O-sulphate transport by the human glutamate transporter, EAAT2. Br J Pharmacol 123:1593-1600. 